\title{
The Network Effects of Core Values on Management Controls
}

\author{
CHRIS AKROYD, Oregon State University
}

STEPHEN JOLLANDS, University of Exeter

NORIO SAWABE, Kyoto University

Acknowledgements - This paper has benefited from the helpful comments on earlier versions made by Habib Mahama, Kohji Yoshikawa, Casey Rowe, participants at the $8^{\text {th }}$ International Management Control Research Conference, participants at MONFORMA 2010, participants at the 4th New Zealand Management Accounting Conference, participants at the 2013 Management Accounting Section Research and Case Conference, and seminar participants at the Department of Operations Management, Copenhagen Business School and Department of Accounting, University of Exeter, Business School. 


\title{
The Network Effects of Core Values on Management Controls
}

\begin{abstract}
:
Simons' (1995b) levers of control have become one of the most prominently utilized management control system frameworks in the accounting literature. In this paper we focus on core values, which guide and motivate an organization, an area of the framework not examined in the accounting literature. Specifically we examine the process through which a new core value develops. We also show how this process is influenced by and acts upon the other levers of control. We highlight how this process initially involves few actors, little complexity and creates a descriptive definition for the core value. This descriptive definition prompts more actors to become involved resulting in greater complexity. The prompt for these actors to become involved is their search and discovery activities aimed at understanding the practical relevance of the new core value. The process of developing the core value and the search for practical relevance necessitates the creation and transformation of other management controls. These management controls in turn change the core value and other actors within the process. The process of search and discovery provides belief control through embedding elements of the core value in the management controls that were created or transformed. While the core value may be displaced its effects on other controls remain in place thus showing how and why controls embody both technical and social elements.
\end{abstract}

Key Words - management control systems; levers of control; core values; actor-network theory JEL descriptors - D83, M14, M41 


\section{Introduction}

The aim of this paper is to investigate core values and how they influence and are influenced by other controls within the management control systems (MCS) of organizations. Specifically, we utilize Simons' (1995b) Levers of Control (LOC) framework to examine the development of a core value and in doing so provide new insight into the operation of what is labeled as belief systems. Previous accounting research (for example see Mundy 2010; Widener 2007) has only to a limited extent examined this area of the LOC and purely from a technical perspective. While belief systems and the corresponding core values may be expressed in technical terms in mission and vision statements, their purpose is clearly related to social control. In this research we contribute to the extant literature through examining the development of a core value and in doing so providing new insight in relation to how social and technical elements of control interact. Thus, in this investigation, through taking a process view of how a core value is developed, we are able to examine a neglected part of the LOC framework, core values, and how they interact with other controls. Specifically, we highlight that it is the need by actors to understand what actions are required to realize these core values in practice that prompts the search and discovery activities that have been ascribed to them. Further, we illustrate how during the process of developing the core value other management controls are created and transformed. These management controls in turn change the core value and other actors within the process. Further we note that even with the disappearance of the original core value the beliefs they were translating may remain embedded in the organization through the management controls that were created or transformed. Thus we highlight how and why management and accounting controls have elements of social as well as technical control, as argued by Chua and Mahama (2007). The combination of social and technical aspects within any given management control highlights how, through belief control, strategy is enacted in the daily routines of all actors within an organization. In order to gather our data and provide these insights we conducted an in-depth qualitative field study.

A number of factors have motivated this research. The first motivation is that within the LOC framework, core values are modeled as social controls but it is not clear how they influence technical controls. Chua and Mahama $(2007,54)$ in particular critique the LOC framework for the separation of beliefs from the other types of controls as follows:

“Simons' 1995[b] categorization of control systems distinguishes corporate creeds and cultural norms (belief systems) from budgetary and variance analysis systems 
(diagnostic systems). In this characterization, accounting is often seen as a "technical" control tool while cultural codes are often cited as an example of "social control". That is, the latter is seen as exercising control via social norms and beliefs while the former is seen as exercising control via "objective" knowledge. ANT [Actor-Network Theory] suggests that this duality can be potentially misleading because it implies that technical control mechanisms do not embody beliefs and values and therefore do not enact social control (Callon 1991; Law 1992). Attempts to see accounting as only a technical tool may obscure the manner in which it operates in perpetuating or transforming particular social norms."

Thus they note that in the LOC framework belief systems and the core values therein, is often seen as a social type of control whereas the other LOC, and more specifically accounting, is seen as a technical type of control. However in practice core values are often defined in descriptive terms and therefore the question remains as to how the corresponding beliefs get embedded within other types of management controls. The comments of Chua and Mahama (2007), as noted above, and the aim to examine the process of the development of a core value and how it interacts with the other LOC guide our selection of ANT as the lens through which we analyze the data we collect from our case study.

The second motivation relates to Simons LOC having been increasingly used as a focus for research within the accounting literature as well as within the broader academic literature ${ }^{1}$ and yet many ambiguities surround this framework (Tessier and Otley 2012). This broad use of the LOC framework, at least in part, can be attributed to its ability to acknowledge the importance of an organizations belief systems (Collier 2005). However, this is perhaps the least understood part of the framework. As Simon's (1995b, 34) notes these belief systems primarily consist of the core values that are critical to the enactment of strategy in the organization. Yet Collier (2005) highlights that accounting research that utilizes the LOC typically does not focus on or make mention of belief systems. Since Collier (2005) noted this, however, LOC based accounting research has increasingly begun to focus more holistically and include belief systems (see for example Mundy 2010; Widener 2007). Mundy $(2010,516)$ specifically notes “[...] the importance of using the framework in its entirety in order to gain a comprehensive understanding of the interface between managers and MCS in their attempts to guide, direct, and control organizational activities." However both Simons (1995b, 2000) and the more recent research 
of Mundy (2010) and Widener (2007) focus on belief systems that are already in place within an organization. Little is known about the process through which core values develop or the role that the other LOC play in this process.

The third motivation comes from the potential importance that belief systems play in regards to the way they can affect the actions of actors within an organization. For example, in relation to scandals such as Enron and WorldCom, evidence (for example see Cahan and Wei 2006; Rosner 2003) suggests that the belief systems of an organization may result in less than desirable behavior within and beyond the boundaries of an organization. A further example is that of sustainability, which is arguably one of the greatest challenges facing society and organizations (Gray 2010; Wackernagel and Rees 1996), with the beliefs around this issue and the core values put in place by organizations being critical in influencing the responses seen to this crisis (Ball and Milne 2005; Milne 1996). It would thus seem that the core values of an organization are important in helping to construct an equitable and just world. Hence, gaining further understanding around how and why these core values influence organizational activity has many potential benefits.

The final motivation is in relation to how strategy is portrayed in the LOC framework as the domain of senior managers with core values being a key signal to employees as to what is of strategic importance. However, little is known of how a core value expands employees' attention and in doing so identify new strategic opportunities. With regard to this Nixon and Burns $(2005,264)$ note that:

\begin{abstract}
"One point that appears to emerge from the empirical reality [...] is that either the management control literature has over-emphasised the influence of diagnostic and interactive controls relative to informal, social controls (the belief and boundary systems of Simons (1995b) framework), or the social controls are becoming more important in the 21 st century."
\end{abstract}

Further Chua (2007) questions where strategy resides within an organization. Specifically if management controls and MCS are utilized to implement and develop strategy then it is unclear as to who enacts it and what the role of core values is in this enactment. As Tessier and Otley $(2012,182)$ note, an ongoing limitation of the LOC is that "[...] employees are considered to be passive actors (see Gray (1990))." Thus

\footnotetext{
${ }^{1}$ Tessier and Otley (2012, p171) note that a search of Google Scholar in 2011 resulted in almost 790 citations of the Simons framework.
} 
through examining core values and their development we aim to provide some additional insight into this ambiguity.

With these motivations in mind this paper seeks to answer a series of questions that aim to clarify some of the ambiguities that surround core values, given their relative importance within MCS. These include; how are core values within an organization developed? How this process is influenced by and act's upon other management controls and actors? What role core values play in enacting strategy and does this provide an understanding of who enacts it? Finally, given the comments of Chua and Mahama (2007), does the investigation into core values provide new understanding of the relationship between social and technical controls?

Through providing insight into these questions, the main contribution of this paper is to provide new understandings of an important area of management control, core values, of which currently there is limited knowledge. In doing so this research contributes to addressing the concerns of Ahrens and Chapman $(2007,3)$ that:

\footnotetext{
“[...] contemporary discussions of management control (e.g. Kaplan and Norton 1996; Simons 1995b) frequently seek to address strategic concerns. They do not, however, tend to elaborate on the specific activities through which their exhortations might be taken up."
}

The use of ANT allows us to gain a new understanding of how core values are formed. The first part of the process establishes what the core value is to be. That is, a descriptive understanding. For example, we may each personally have a core value that states that 'we wish to be good people'. However this alone does not provide us much meaning around what must be done to be a good person let alone what a good person is. Hence a second part to the process is needed to establish what must be done to achieve the core value. That is, as Ahrens \& Chapman $(2007,21)$ state "[...] we can see the way in which the precise nature of objectives [...] arises from daily activity as much as daily activity is shaped by those objectives." Thus in relation to our example the second process provides to us meaning about what a good person is and what must be done in order to be one. Through tracing the associations that form as actors are enrolled into and defect from the networks under construction, ANT provides the means for investigating and understanding the process of developing a core value within the case organization and thereby addressing our research questions. 
The remainder of the paper is organized as follows. In section two we provide a brief overview of the LOC and the developing accounting literature that utilizes them. We then in section three provide an overview of ANT and explore its usefulness in investigating the process of developing a core value. As Justesen and Mouritsen (2011) note there are potentially many different understandings of ANT. Therefore in this section we outline the general understanding that we draw upon as well as outlining specific concepts from ANT that are brought to bear in our analysis. This is followed by an overview of our case site organization and research method, in section four. In section five we trace the process of developing a core value at our case site organization and then draw out implications in section six before concluding in section seven.

\section{Simon Levers of Control}

Simons LOC framework has seen wide use within the accounting literature (see for example Bisbe and Otley 2004; Kober et al. 2007; Mundy 2010; Widener 2007). In providing a brief overview we first note that the LOC consists of four interdependent systems that play off the inherent tensions within organizations to implement strategy. The first of these, which this paper primarily, but not exclusively, concentrates on, are the belief systems. Simons $(1995 b, 34)$ defines belief systems as “[...] the explicit set of organizational definitions that senior managers communicate formally and reinforce systematically to provide basic values, purpose, and direction for the organization". Mundy $(2010,501)$ notes that "[...] these definitions are stated in broad, valueladen terms, because the purpose of a belief system is to inspire organizational search and discovery without prescribing the precise nature of the activities." As outlined above, belief systems primarily consist of the core values of the organization. Thus we can view the core values that make up the belief systems as "strategy as "perspective"" designed for "obtaining commitment to the grand purpose" (Simons 1995b, 159). That is an organizations' core values provide positive direction for employees to search out opportunities for implementing strategy.

The second LOC are boundary systems, which outline the areas in which the organization plans to operate or as Simons $(1995 b, 39)$ states “[...] delineate the acceptable domain of activity for organizational participants." Boundary systems are seen as a negative control in that they are designed to focus attention, which has been expanded through belief systems, only on actions that enable the organization to implement the desired strategy. Thus we can understand boundary systems as "strategy as "position" designed for "staking out territory" (Simons 1995b, 159). 
The third lever are the diagnostic control systems that supply information and feedback to management on the efficiency and effectiveness of the operation and are "[...] designed to ensure predictable goal achievement" (Simons 1995b, 59). Diagnostic control systems are designed to assist in the implementation of intended strategy (Mintzberg 1978). Thus we can understand diagnostic control systems as "strategy as "plan"” designed for "getting the job done" (Simons 1995b, 159).

The final lever are the interactive control systems that aid learning and dialogue particularly in regard to strategic uncertainty and "[...] are formal information systems managers use to involve themselves regularly and personally in the decision activities of subordinates" (Simons 1995b, 95). Interactive control systems are designed to identify and assist in the implementation of emergent strategy (Mintzberg 1978). Thus interactive control systems can be understood as "strategy as "patterns in action"” designed for "positioning for tomorrow" (Simons 1995b, 159). The four LOC are depicted in figure 1 below, which is based on figure 7.3 in Simons (1995b, 159):

\section{Insert Figure 1 Here}

It should be noted that in Simons $(1995 \mathrm{~b}, 159)$ original figure 7.3 , and as reflected in figure 1 above, the interdependent nature of the four LOC is reflected in the title of the figure being "A Dynamic Relationship". This acknowledges the ongoing interplay between the various types of control and the influence they have upon each other. Yet, surprisingly, this understanding is not fully reflected in the literature itself and perhaps is the source of some of the critique the LOC framework has received (see for example Collier 2005; Tessier and Otley 2012).

This gap of understanding can be seen even in the works of Simons. Looking at his earlier works (Simons 1987, 1990, 1991) we can understand that the strength and development of the LOC framework stems from being the first studies to provide empirical evidence of a relationship, only previously referred to on a theoretical level by the likes of Otley (1980) and Dermer (1977), between accounting control systems, business strategy and firm performance. Within these works we see the first vague reference to core values but only in relation to understanding how controls are used interactively. That is Simons' $(1991,50)$ notes that "[t]op managers focus their attention on strategic uncertainties that could derail their vision for their future and use selected systems interactively to focus the attention of the entire organization on these uncertainties." Further, he acknowledges that the control selected to be used diagnostically may change as "[a] new top manager may 
bring a new vision to the organization” (Simons 1991, 61). Thus in his early works, Simons' $(1987,1990,1991)$ interests are primarily with the relationship between accounting controls and strategy, with only passing reference to other types of control, with no understanding of how they all interact in a dynamic relationship.

The full versions of the LOC, which include reference to belief and boundary systems, are presented in Simons (1994, 1995a) before a more in-depth version in Simons (1995b) and subsequent refinement in Simons (2000). Specifically, in regards to the focus of this paper, we see in this book that he continues to refine the LOC framework the most in-depth explanation of core values as follows:

\begin{abstract}
"To ensure that employees engage in the right type of activities, managers must first inspire commitment to a clear set of core values. Core values are the beliefs that define basic principles, purpose and direction. Often rooted in the personal values of the founders, core values provide guidance about responsibilities to customers, employees, local communities, and stakeholders. They explicitly define top management's views on trade-offs such as short-term performance versus long-term responsibilities. Core values provide guidance to employees where rules and standard operating procedures alone cannot suffice." (Simons 2000, 276, emphasis in original)
\end{abstract}

It is also of interest that a few years after this book was published Simons became involved in producing a paper (Simons et al. 2002) that directly asks CEOs of large organizations to re-examine the basis of these very core values. However, throughout these works core values is the one area that receives the least amount of attention. For example, throughout his works Simons only ever examines core values that are already established and as a result very little is known about how and why these are developed. Further, very little is known about how core values interact with other controls beyond, as we mention above, boundary controls being in place to focus the attention of organizational members who have been inspired into search and discovery activities by these core values. Thus in a way our understanding of this dynamic relationship is still underdeveloped. Hence, it is our aim to contribute to the literature through providing insight into the area of the LOC that has had the least attention and in doing so provide new understanding around the dynamic relationship that exists between all four of the LOC. 
These limitations prompted Tessier and Otley (2012) to conduct a conceptual development of the LOC framework. However, in doing so they only reference Simons (1995b) and it should be noted that since this book he has further developed and clarified the LOC. Specifically in Simons (2000) we see the development of and clarification of many of the ambiguities noted by Tessier and Otley (2012) ${ }^{2}$. Further, still in Simons (2005), even though the levers of control are de-emphasized, with belief systems being repackaged into "shared purpose" ( 169), it is of interest that it deals with a number of elements missing from Tessier and Otley's (2012, 182) revised framework, namely issues around organizational structure and spans of control. Even with this conceptual development, knowledge of the dynamic relationship between the various control elements and specifically understanding of core values is still limited.

An important point made by Tessier and Otley (2012), however, is that the accounting literature that utilizes the LOC framework also has the same limitations, as mentioned above, as the original work upon which they are based. This is not surprising given that the adoption of the LOC as a useful framework within the accounting literature only began to occur at the turn of this century and as a result is in its relative infancy. As Ahrens and Chapman (2004) note the earlier accounting literature that utilized the LOC typically only focused on understanding diagnostic and interactive controls and the relation between the two. Thus, this type of research focused on topics such as the use of budgets (Abernethy and Brownell 1999), on non-financial management accounting change (Vaivio 1999), and on innovation management (Bisbe and Otley 2004). This however was soon criticized (Collier 2005; Mundy 2010) as focusing only on half of the LOC can at best provide a partial understanding of how MCS work in practice.

Thus research within the accounting literature has expanded to include a more holistic view of MCS through not only investigating diagnostic and interactive control systems but also through the examination of belief and boundary systems. Examples include Bruining, Bonnet \& Wright (2004) who note that there is a need to develop coherence between strategy and all four LOC subsequent to a management buyout; Tuomela (2005) who finds that not only are strategic performance measurement systems used diagnostically and interactively but also that these systems have implications for belief and boundary systems; and Widener (2007) who examines the existence of mission and vision statements and the extent to which senior management hold them to be important.

\footnotetext{
${ }^{2}$ This is not a critique of Tessier and Otley (2012) as their paper provides a valuable clarification of many terms and concepts that surround Simons LOC that is helpful given, as they note, the many ways in which these terms and concepts have been understood and used within the accounting literature. Whether or not the refined framework they develop has merit is for future empirical research, a point they make themselves, and not the focus of this paper.
} 
From the above discussion we can see that similar to the original works of Simons, the accounting literature has focused on how things are, that is the LOC in place, rather than on how they interact, the dynamic relationship. This has resulted, at least in part, from the research methods typically employed in the accounting literature being better suited to understanding the LOC in place rather than the dynamics of the relationship between the LOC and providing insight into core values. For example, Widener (2007) conducted a survey of 122 Chief Financial Officers and in doing so established the existence of mission and vision statements and the extent to which senior management hold them to be important. This, however, provides little insight into core values. Further, Widener $(2007,757)$, through the use of a structural equation model, “[...] suggests that there are multiple inter-dependent and complementary relations among the control systems." However, establishing the existence of these relations still gives us limited understanding of how these develop and change over time and thereby knowledge around the dynamic relation between the LOC.

However, it must be noted that the use of these methods has advanced our extant knowledge of many areas of the LOC framework. The question that arises from our discussion above is what theoretical framing is appropriate in order to be able to research an object, a core value, which is less tangible, compared to traditional accounting controls. Our starting point is to examine the nature of the relationship between belief systems and core values. As we outline above Simons $(1995, \mathrm{p} 34)$ definition of belief systems is “[...] the explicit set of organizational definitions that senior managers communicate formally and reinforce systematically to provide basic values, purpose, and direction for the organization". In this sense we can see that the belief systems are the spelling out of senior managers' intention for the organization. Ultimately whether this transpires to the other organizational actors having the same intention is only discernible in their actions. That is the link between intention and belief systems is that the former, which is only discernible in action, is the embodiment of beliefs. However, senior managers have the problem that the actions of the other organizational members always occur in the future and it is therefore only with hindsight that they can judge whether their intentions have been put into practice, This therefore gives rise to a need for senior management to find ways in which they can align the future actions of organizational members with their intention for the organization. We therefore see a core value as an actor enrolled by managers in order to influence action and thereby in turn intention and belief.

This understanding of the link between belief systems; the values, purpose, and direction; and core values; the vehicle used by senior management to try and influence what happens in the future; identifies ANT as the most appropriate theoretical framing to analyze our collected data in relation to our research aim and questions. With the process orientated nature of ANT and its often quoted mantra of "follow the actor" (Latour 
1987) it has much to offer in relation to examining the development of a core value. Hence we see that from an ANT perspective a core value is an actor enrolled by senior management in order to enroll other actors into supporting their interpretation of their programs in relation to the organization. Thus in our case study it is the very process of a core value becoming that we examine in order to unravel this very history (Callon 1986a) in order to provide insight into and understanding of the core value, how it interacts with other actors including other aspects of the LOC, how it assists with the enactment of strategy and the relationship between social and technical controls. We, therefore, in the next section turn to outlining the critical concepts from this theoretical framing that we mobilize in our analysis.

\section{Theoretical Framing: Actor-Network Theory}

Our use of ANT is appropriate as it allows the recognition that core values, as with all actors, have the potential to materially affect the operations of an organization. Indeed, as we outline above, it is for the very reason of enrolling organizational actors into their translation that senior management utilize core values. That is senior management enroll core values in order to act upon other organizational actors in a way that produces future action that is in line with their intention. Further, ANT allows us to see the conflicts and controversies that may arise due to the core value in question having the potential to prompt change. Finally, ANT allows for us to understand that this all occurs in a complex and messy social context (Chua and Mahama 2007). However, in utilizing ANT we must recognize that it has its own unique "[...] emphases, ambitions, and means of analysis" (Mouritsen et al. 2010, 293). ANT allows us to understand the organization as a network of human and nonhuman actors held together through a series of associations that are constantly made and remade as actors are enrolled into and leave the network.

Justesen and Mouritsen's $(2011,161)$ suggest that ANT enables the researcher to place the research object, in our case a core value, at the centre of the research. After all "[...] almost all of our interactions with other people are mediated through objects of one kind or another" (Law 1992, 381-382). Thus, ANT is "[...] relationist: showing the relationship between the points of view held by mobilized and by mobilizing actors gives judgments as fine a degree of precision as one could wish for" (Latour 1991, 128). As Law (1992, 390) notes:

"So it is that actor-network theory analyses and demystifies. It demystifies the power of the powerful. It says that, in the last instance, there is no difference in kind, no 
great divide, between the powerful and the wretched. But then it says that there is no such thing as the last instance. And since there is no last instance, in practice there are real differences between the powerful and the wretched, differences in the methods and materials that they deploy to generate themselves. Our task is to study these materials and methods, to understand how they realize themselves, and to note that it could and often should be otherwise."

Thus ANT provides a way of avoiding the "[...] traditional sociological dichotomies, such as micro/macro, subject/object, structure/agency and technical/social" (Justesen and Mouritsen 2011, 177). This therefore allows us in this research the opportunity to unravel the concerns of Chua and Mahama (2007) around how the LOC framework seemingly artificially divides controls into social and technical.

If we understand the economy to be a sub-system of society then ANT “[...] implies that the economy is an achievement rather than a starting point or a pre-existing reality that can be revealed and acted upon" (Çaliskan and Callon 2009, 370). As Mackenzie $(2009,441)$ notes this equates to a performative understanding where economic practices, including those of academics theorizing with regard to economics (Callon 2007), take an active role in the very construction of the economy. This in turn implies that "[o]rganizations do not have to be placed into a 'wider social frame' since they themselves give a very practical meaning to what it means to be nested into a 'wider' set of affairs." (Latour 2005, 7)

The underlying assumption of the continual construction of society, and the sub-system that is the economy, has profound implications for approaching research. Most importantly is the need to follow the actors in order to understand their practices (Latour 1987). But in doing so it is important to keep in mind that "[...] instead of taking a reasonable position and imposing some order beforehand, ANT claims to be able to find order much better after having let the actors deploy the full range of controversies in which they are immersed" (Latour 2005, 23, emphasis in original). Law (1992, 380, emphasis in original) makes this point succinctly by noting that "[i]f we want to understand the mechanics of power and organization it is important not to start out assuming whatever we wish to explain." Thus in this research, we select a core value and follow it as it travels through time and space, noting how it interacts with, acts upon, and is changed by the other actors that it comes into contact with.

We note that Chua (1995) observes that as ANT has previously been used and explained in depth in the accounting literature (see for example Alcouffe et al. 2008; Briers and Chua 2001; Cuganesan and Lee 2006; 
Mouritsen et al. 2001) providing a full description is not necessary since this has been done before. However given the implications of different versions of ANT being available (Justesen and Mouritsen 2011) for the purposes of this paper we provide an overview of the concept of translation, a central concept from ANT that we utilize in order that we can be clear about the assumptions being made.

Translation is a process an actor or actors start with a certain purpose in mind. However, the success of achieving their goals is never guaranteed. (Callon 1986b, 1986a). Thus:

\begin{abstract}
"By translation we understand all the negotiations, intrigues, calculations, acts of persuasion and violence, thanks to which an actor or force takes, or causes to be conferred on itself, authority to speak or act on behalf of another actor or force [...] Whenever an actor speaks of 'us', s/he is translating other actors into a single will, of which s/he becomes spirit and spokesperson.” (Callon and Latour 1981, 279)
\end{abstract}

Therefore to translate is to displace the goals and interests of others and to speak on their behalf promoting your own goals and interests as those of the collective, thereby, through presenting yourself as representing the collective, displacing the very others for whom you would speak (Callon 1986b, 1986a). It is clear to see that a core value would have an important role in this process. Thus an integral part of translation is the maneuvering of an actor to become the spokesperson for a collective they have defined. Further, in relation to becoming spokesperson for the given collective, Callon $(1986 \mathrm{~b}, 176)$ notes that the way in which actors make themselves indispensible is to define the issue in such a way that its resolution can only be reached through the obligatory passage points (OPP) of their program of investigation. Chua and Mahama (2007, 53) suggest that OPP are typically only successfully constructed by "strong" or "more influential" actors "[...] who occupy convergent nodes through which all information must pass." Thus " $[\mathrm{t}] \mathrm{o}$ translate, then, is to oblige an entity to consent to detour" (Callon 1986a, 26).

Displacement does not require the actual removal and replacement of the goals and interests of those being displaced but rather the perception that this has occurred. Thus as Callon (1986a, 32) notes "[e]ntities are strong because each entity gathers others." However this does not equate to any actor being able to translate anything. Rather the ability to translate, and thereby perform displacement, is highly dependent on the translations that have gone before to the point where the translations that are possible to be performed now may be predetermined by those that occurred in the past (Callon 1991) 
Therefore the outcome of a successful translation is equivalence (Callon 1991; Law 1992) or the perception that things are the same when they actually may not be (Law 1999). Or in other words the transformation whereby "[...] one thing (for example, an actor) may stand for another (for instance a network)" (Law 1992, 386). However defining the term does not tell us how these associations are made and remade in the act of performing translation (Law 1999). Rather the process of translation involves the forming of associations, which in turn form networks, of actors from the conceptualization of an issue through to where a particular solution to the issue is taken for granted (Latour 1987, 1999).

However as Callon (1986a, 26) notes "[t]ranslation cannot always be taken for granted and the strategies used depend upon the particular circumstances in which they develop." That is during translation the network being formed is far from being stable and is open to challenges (known as 'trials of strength') from other entities (known as 'counter-actors') with their own agendas (known as 'anti-programs') (Callon 1986b, 207-8). As Callon (1986b, 224) notes “[...] from translation to treason there is only a short step [...]" with these trials of strength determining how the translation proceeds. After all "[e]ach entity enlisted [...]" into the translation "[...] can submit to being integrated into the initial plan, or inversely, refuse the transaction by defining its identity, its goals, projects, orientations, motivations, or interests in another manner" (Callon 1986b, 207)

The translation process is not linear but rather a recursive and iterative process. ANT recognizes the complexities of reality and the interconnections that may and can form between many varied actors. Further ANT recognizes that human and non-human actors, such as a core value, are all important and can and may become connected within this process. Therefore we see that "[...] any division we make between society on the one hand and scientific or technical content on the other is necessarily arbitrary." (Latour 1991, 106)

Thus, as this demonstrates, and as Mouritsen et al (2010, 301) further note, the construction of management controls, including core values, and MCS is part of the translation process. Therefore in order to be able to research these objects we must focus on their location within the larger group of associations that form the network of which they are part. Mouritsen et al $(2009,751)$ suggest that the implications of taking this understanding is that these objects should not be viewed as "[...] effective management control systems [...]" but rather as actors in a network of actors that act and participate in the translation of their network. Thus within the context of innovation management a "[...] management accounting calculation does not describe or represent innovation and sourcing activities in any detail, but it adds perspective to them and relates them to the firm" (Mouritsen et al. 2009, 752). Like all actors, management controls and MCS do not gain their strength 
through being inherently good or effective but rather through their abilities to enroll and mobilize others (Mouritsen et al. 2009, 751).

To better understand this view of management controls and MCS we draw upon Latour's (1991) example of the European hotel key. This example links with the definition of MCS as the mechanisms actors use to enable the achievement of their goals and those of the wider network to which they belong and include a mixture of both formal and informal processes and procedures (Bisbe and Otley 2004; Kober et al. 2007).

The European hotel key example investigates European hotel manager's efforts to ensure that their customers leave their room keys at reception prior to leaving the hotel. The rationale behind wanting customers to leave their keys prior to spending time away from the hotel is that in doing so they can limit the possibilities of keys being lost. Thus the hotel managers use a number of different measures that they deploy successively in order to enroll customers into their program. Firstly the hotel manager asks the receptionist to remind customers as they check in to leave their keys at reception when going out. This will result in enrolling a small percentage of customers into the hotel manager's program but will not be sufficient in and of itself to enroll all customers. Thus the hotel manager takes the further step of placing a sign near the exit to remind customers to return their keys. Again this may enroll more customers into the hotel manager's program but it is not until the hotel manager adds a large, cumbersome weight to the key that a majority of customers become enrolled. The large, cumbersome weight acts on the hotel guests by making their "[...] pockets bulge and weighs down their handbags: they go to the front desk on their own accord to get rid of it" (Latour 1991, 104).

From this example we can see that the verbal reminder, sign, and weight are the mechanisms the hotel manager uses to achieve his goal of limiting the possibility of losing keys. Hence we can see that individually the verbal reminder, sign, and weight are all what we label management controls. Further we can recognize that the hotel manager requires each one as none alone can help to assist in achieving their aim. For instance without the verbal reminder and signs the likelihood is that a large number of the customers will take their keys with them rather than returning them to reception and experience displeasure at having to carry such a large and cumbersome object. Hence we see that together they form a system of management controls with the aim of achieving the goal of the hotel manager.

We also note that the design of these controls will impact on the effectiveness of achieving the goal. As Latour $(1991,105)$ notes: 
"If a weird client could break the ring connecting the light key to the heavy weight, the innovator would then have to add a soldered ring to prevent such breakage. This is an anti-anti-program. If a paranoid hotel manager wanted to ensure zero key loss, he could place a guard at each door to search the customers - but then he would probably lose his customers instead."

So it is for an organization. How they design the individual controls within their MCS will determine the outcome of their operations. This links to Ahrens and Chapman's $(2007,24)$ statement that "[...] the key question for management control theory is not how to constrain individuals and overcome resistance. Rather, it needs to bring into focus the possibilities of management control systems as a resource for action." As we shall see this also applies to the core values in that the presence of one does not automatically result in the desired outcome. Rather, they are there to promote the desired search and discovery activities through prompting other actors to experiment as to what must be done in order to achieve the core value and in turn the goals of the senior management.

Finally it is important to note the relation of MCS frameworks, such as LOC, to our ANT derived understanding of management controls. As researchers we enroll MCS frameworks to assist with our analysis. We utilize these frameworks to label and classify what we find in the field in such a way that it provides meaning for ourselves and our peers. Thus, we are in effect no different to the scientist that Latour and Woolgar (1986, 36-37) refer to in the following:

"In sum, then, our discussion is informed by the conviction that a body of practices widely regarded by outsiders as well organized, logical, and coherent, in fact consists of a disordered array of observations with which scientists struggle to produce order. [...] Despite participants' well-ordered reconstruction and rationalisation, actual scientific practice entails the confrontation and negotiation of utter confusion. The solution adopted by scientists is the imposition of various frameworks by which the extent of background noise can be reduced and against which an apparently coherent signal can be presented." 
Hence, it is to be expected that various MCS frameworks will have differing strengths and weaknesses as they struggle to produce order over the complexities of data derived from organizations. Perhaps the popularity and widespread use of Simons LOC relates to its relative strengths being greater than its weaknesses. It is our aim in developing and contributing to the understanding of core values, in what follows, that we will improve the effectiveness of this framework for future researchers.

\section{Research design and methods}

The longitudinal case study that we use in this research focuses on an organization, Kiwi, that is engaging with a particular issue, sustainability (Wackernagel and Rees 1996), which has the potential to challenge its existing core values. In doing so we acknowledge that sustainability is an important but contestable and broad concept (Ball and Milne 2005; Gray 2010). However it is not our intention in this paper to enter the debate of what sustainability is or can be. Rather the focus of this paper is to investigate the process through which a core value evolves. Therefore for the purposes of this paper the concept and issues surrounding sustainability, whatever they may be, merely provides us with the context in which to examine the emergence of a new core value in an organization. It is in fact the contestable nature of sustainability that allows us the opportunity of studying the process of developing a new core value as the actors within the case organization struggle to understand and respond to such an ambiguous concept.

Our case organization 'Kiwi' is the New Zealand manufacturer of a large well known multi-national organization which competes in the fast moving consumer goods industry. Kiwi employs approximately one thousand people across sixteen sites located throughout New Zealand. Kiwi competes in all product lines within its market segment, being the market leader in two of these. It offers a range of internationally recognized brands along with local brands including one that is widely recognized as a New Zealand icon.

Kiwi operates as if it was a wholly New Zealand owned company, as demonstrated by its employee proposition 'Refreshingly Kiwi' but legally it is the New Zealand operations of an Australian listed company, 'Koala'. Koala's head office is in Sydney, Australia and along with operations in New Zealand and Australia they also operate in Fiji, Papua New Guinea, and Indonesia. Across these five countries, Koala employs over fifteen thousand people, has over seven hundred thousand active customers who provide them with access to over two hundred and sixty five million consumers. In 2009 Koala had revenue of just over four and a half billion Australian dollars and EBIT of close to eight hundred million Australian dollars. 
Koala is in turn thirty percent owned by a USA based company, 'Eagle', on whom they are reliant for global marketing and the secret ingredient of their most famous product. Eagle has a history of over one hundred and thirty years and has over three hundred companies, of which Koala is one, manufacturing its products in over two hundred countries. Through their thirty percent stake in Koala, Eagle has the right to appoint two out of the eight directors of Koala. This combined with holding the secret ingredient and controlling global marketing allows Eagle significant influence over the operations of Koala. Thus when Eagle signaled sustainability as an important issue that should be engaged with Koala, and Kiwi in turn, were also compelled to begin to understand what this entailed.

\section{Data collection and analysis}

The majority of the data was collected between June 2008 and November 2009 and covered the activities of the case organization from 2004. The data, as summarized in Table 1 below, was collected via interviews, observations, and document analysis. Through the data collection process we were seeking to be able "to articulate organizational members' theories-in-practice and their motivations as well as the ways in which they relate to observed activities in the field" (Ahrens and Chapman 2006, 825).

\section{Insert Table 1 Here}

In 2008 the data collection involved attending three corporate presentations. Two of these presentations were given by senior managers of the case organization. The third was given by a project manager of the finance department through whom research access was negotiated. These presentations provided us with the opportunity to gain an understanding of the suitability of the organization for this research. Further it provided us with an initial understanding of the case organization prior to more formerly entering the field. The presentations covered a wide range of information including the background to the case organization, details of chosen strategy, how competitive advantage was achieved and maintained, and the specific sustainability related issues they faced. Our background understanding of the case organization was further deepened through a review of publically available data from the internet, annual reports, and sustainability reports.

Subsequently, in 2009 we formerly entered the field to collect data through interviews and observations. In total we conducted twenty three and a half hours of interviews with all the relevant actors within the Kiwi network and key actors from associated networks in order to trace the translation of the core value being focused on. Following Ahrens and Chapman's (2006, 833) warning "not to take for granted stability 
in management accounting systems, their uses, and organizational roles" we also performed close to nineteen hours of observations. These observations allowed us the opportunity to deepen our understanding via seeing first hand key activities in practice. During this time we also viewed and analyzed numerous externally and internally available artifacts. This included information from websites, the organizations intranet, management reports, traditional management controls (such as budgets) and more issue specific management controls (such as the organizations carbon footprint report and supporting calculative spreadsheets).

During data collection we began the process of analysis with the aim of "iteratively seeking to generate a plausible fit between problem, theory, and data" (Ahrens and Chapman 2006, 836). Analyzing the data in this way allowed us to exit the field only once we were confident that we had fulfilled our research aim. In 2010 we conducted a follow up interview with an actor from Eagle. This actor's role within Eagle of Sustainability Initiative Lead for the South Pacific required him to interact with key actors within Koala and Kiwi as they confronted their sustainability related issues. As a result this actor has in depth knowledge of the translation process at Kiwi that we have researched. This interview provided us with the ideal opportunity to gain further confidence for the validity (Ahrens and Chapman 2006) of our findings as presented in the following two sections.

\section{Translation of a Core Value at Kiwi}

The data from the case organization, Kiwi, traces the forming of associations and the translation process of the development of a core value focusing on sustainability. The first part of the translation involves few actors and establishes the definition for the core value. Subsequently the translation is reliant on this definition to create the space for it to continue, involves many actors and enables the core value to act in its role of prompting search and discovery.

The focus on sustainability issues at Kiwi began in early 2004 with actions being taken by many different actors in order to try and influence Kiwi's approach. Most influential were the actions taken by Eagle and Koala. A video produced by Eagle that they circulated internally within their extended and associated networks is an example that typifies the types of actions taken. In this video images of Ghandi, Aung San Suu Kyi and Ang Lee are presented alongside historic and iconic images of Eagle in an effort to urge those within the extended networks to take action with regards to the issue of sustainability. This is further enforced through the statements that "If we consume what we do today we will need the resources equivalent of 4 planets" and "by redesigning the way we work and live so that sustainability is part of everything we do"; images of masses 
of waste; recycling efforts; renewable energy sources; and making promises to "grow our business, not our carbon", "always reuse the waste we generate", and "give back every drop of water we take". Thus this artifact is clearly constructed with the purpose of influencing Eagle's associated networks, including Koala and Kiwi, and thereby prompting them into taking action in respect to sustainability issues.

Koala also took steps to start influencing the actions of Kiwi. Foremost of these were the implementation within Operations of four sustainability focused KPIs known as the environmental performance metrics (EPM). These were namely water usage, energy usage, waste minimization, and recycling level. Koala developed a spreadsheet to collect data for these and required Kiwi to collect the data and report the results to Koala. However for many years these EPMs were limited to data collection within the Operations department and the emphasis placed on them by Koala was mostly irrelevant and therefore ignored in Kiwi. This was because in Australia water shortage is one of the greatest ecological problems faced. For this reason Koala placed most emphasis on the EPM that measured water usage and channeled their efforts into improving this EPM. However in New Zealand water is in relatively plentiful supply resulting in the emphasis placed by Koala on the water usage EPM being mostly meaningless for Kiwi ${ }^{3}$. Thus at Kiwi these EPMs were, at best, being used diagnostically.

However as a result of the combined efforts of Eagle and Koala, as exemplified above, Kiwi began to act. Initially this involved the New Zealand Leadership Team (NZLT) discussing what the appropriate response should be. Within a short period of time the NZLT had decided the appropriate course of action should be to develop a core value around sustainability. In short this core value was that sustainability was an important issue that society faced and one in which Kiwi wanted to be seen as an 'emerging leader'.

Thus the start of the translation developed a descriptive understanding of the core value that was designed to be part of Kiwis belief system. Therefore at this stage the core value is an actor enrolled by the NZLT in order to influence action and thereby in turn intention and beliefs. However the core value alone was not effective in and of itself for Kiwi to comprehend what must be done in order to achieve what it stated. That is, the core value, like all core values, was outlined in broad terms and therefore did not define what must be done in order for Kiwi to be seen as an emerging leader in sustainability issues. It did, however, create the required space within which the translation could continue. That is, it prompted actors to search and try and discover what Kiwi might have to do to be seen as an emerging leader in sustainability issues. This would

\footnotetext{
${ }^{3}$ In making this statement we note that this is a common perception among New Zealanders ((Ministry for the Environment 2009a)), including those within Kiwi, rather than a reflection of the real quality and supply of
} 
require, among other things, the imposing of identities as to who was to be doing the judging of the emergence, the definition of sustainability issues, and in this context what an emerging leader is.

The translation continued with the Managing Director (MD) of Kiwi signaling to the actors within Kiwi that this was an important area of uncertainty. It is important to note that at this stage so much yet had to be determined. As a result the core value was still being communicated informally rather than as part of the inscriptions that made up the formal belief system. In this way the NZLT was allowing for a greater degree of freedom for actors within Kiwi to construct their identities in relation to the new core value than had it been inserted into the formal belief systems of mission and vision statements.

This initial identification by the MD resulted in what Callon (2009, 543) labels as "multiform problematization" or "a network of problems [...] whose content and extension evolve in relation to the translations that are attempted between problems." That is, due to sustainability being a contestable and ambiguous concept (Ball and Milne 2005; Milne 1996) constructing an identity for it proved problematic but was required as part of understanding what it is to be an emerging leader in sustainability issues and in identifying those that would see Kiwi as such.

Therefore this multiform problematization required multiple actions that enrolled multiple human and non-human actors in order to experiment as to what this core value meant within the context of Kiwi. Hence, we see that through management enrolling the core value, the resulting search and discovery actions are prompted by the need of actors to construct identities in relation to it. That is experimentation is prompted and undertaken by the need of actors to understand what must be done within their context to implement the core value in practice.

The initial action taken was the 2004 hiring of the Corporate Affairs Manager to promote the external image of Kiwi with a particular emphasis on sustainability related issues. A large part of this revolved around the producing of a sustainability report. It was decided that this should be a stand-alone report distinct from the reporting of financial results as Kiwi only reported these in the combined group annual report. The first of these was produced by Kiwi for the 2006-7 financial year and was printed directly on cardboard packaging ${ }^{4}$. This

water within New Zealand. Evidence suggests that potentially this is not actually the case in New Zealand ((Ministry for the Environment 2009c, 2009b; Verburg et al. 2010))

${ }^{4}$ That is, the report was printed directly onto the corrugated cardboard that normally would have been made into boxes used for the transportation of Kiwi's products to their customers. The corrugated cardboard was as if it had been taken directly off the production line with logos of the corresponding product visible at places throughout the report. Thus each report was unique in that it depended on which part of the box a certain page was printed onto as to what image (e.g. product logo, barcodes, "please recycle" logos, etc) is visible below the printing that was superimposed onto it. However, we were informed by the Corporate Affairs Manager that the 
report outlined current achievements and future goals in the four areas; as determined by Eagle; of marketplace, workplace, community, and environment. However no dedicated information system was set up in order to produce this report. Rather the information was personally gathered by the Corporate Affairs Manager through talking to the respective actors in the areas of interest. This included asking the Integrated Management Systems Manager for the data from the tracking of the four sustainability focused EPMs.

The network being assembled during the multiform translation was further strengthened through the addition of a spokesperson - the Chief Financial Officer (CFO). The CFO signaled this as an area he wanted to take leadership in. The CFO was seen to be powerful in potential (Latour 1986) due to being a 'leader of leaders' and having key non-human actors, which included the calculative architecture of the accounting system, in his network. The CFO mobilized his network into supporting the actions taken towards the development of the required understanding and thereby further stabilizing the identity of the core value.

One of the first actions put into motion by the new spokesperson was the forming of a cross-functional team - the 'Imagineering Team' - to focus efforts. The Imagineering Team was specifically charged with engaging with initial efforts to develop the actions required to implement the core value. In other words the Imagineering Team had as its remit to develop knowledge around sustainability, what it meant to be an emerging leader in this context, and who the audience was to judge Kiwi as such.

An outside consulting firm, 'Consult', was engaged to assist the Imagineering Team in their efforts. Consult had previously been engaged to assist with preparation of the sustainability report and had mainly been chosen due to their founder being a previous work colleague of the Corporate Affairs Manager. Consult used this new consulting opportunity to increase their importance to Kiwi. They did this through trying to impose the identity of those that would judge whether Kiwi was becoming an emerging leader. That is, they tried maneuvering to become an obligatory passage point (OPP) to a market demographic increasingly perceived as important by Kiwi. This demographic was labeled as Lifestyles of Health and Sustainability (LOHAS) who were seen as conscientious consumers whose purchases were driven by a set of beliefs focused on healthy living and sustainability ideals. Consult provided 'facts' (Baxter and Chua 2003) that 'proved' that LOHAS was an increasingly expanding group which potentially could be a key demographic for Kiwi as commented upon by the CFO:

particular product line that this corrugated cardboard packaging related to had been discontinued and therefore had it not been used for this report then it would have been discarded. 
"There is, sort of, conscientious consumer group [LOHAS] span all of those income groups and sits at around between thirty or forty percent. So whether they gain momentum and really do mainstream [...] then that will probably be the biggest question."

Regardless of Consult's efforts to influence, the Imagineering Team sessions acted upon those involved. Once members returned to their respective areas they started taking actions in relation to those areas in order to experiment so as to develop knowledge around sustainability, what it meant to be an emerging leader relative to their areas context, and who the audience was to judge Kiwi. An example of this is provided by the Procurement / Logistics Manager:

"Yeah, $[\ldots]$ we've run a session with $[\ldots]$ we're in a session with our suppliers last year. We've invited them openly as part of a formal process called 'The Supply Challenge' to come to us with ideas about how we can make our business more sustainable."

Along with a drive to enroll associated networks into their efforts the Procurement / Logistics Manager was also responsible for enrolling other sustainability related management controls within his area. Foremost amongst these was a sustainability focused procurement guidelines, which acted upon procurement decisions to make sustainability issues a consideration. The implementation of the new procurement guidelines can be seen in the following example given by the Procurement / Logistics Manager:

"We have a huge fleet of $[\ldots]$ Reps vehicles and [...] there are still a lot in the fleet at the moment [...] Vitaras which I think use [...] 13.2 litres of petrol per one hundred kilometres. Now I personally drive a XR8 which is a V8 and my car's more fuel economic than a [...] than the Reps vehicles got on the road, they're four wheel drives $[\ldots]$ so we did a lot of work on finding a vehicle that would be [...] a lot [...] more $[\ldots]$ fuel efficient so we've basically halved our fuel costs $[\ldots]$ on the vehicles we've now put in. We've put the VW Golf 1.9 litre turbo diesel [...] So that, you know, the parity piece between petrol and diesel, we know diesel is a lot cheaper 
than petrol, great $[\ldots]$ but now we've gone from [...] 13.2 litres per hundred kilometres to something like 5.6. So we've actually seen nearly a sixty percent decrease in our $[\ldots]$ fuel cost on the vehicles we've put in $[\ldots .$.$] so the purchase price$ of the Golf was higher but the total cost of ownership of the Golf is a lot cheaper because the service intervals are longer [...] all those sort of things. And VW is, sort of, seen as a leader with their blue motion technology as well. So from a market placement it was a good branding opportunity for us as well to, I suppose, use [...] you know, what was seen to be best leader in the market and aligning ourselves to them."

Other measures taken as a result of the new procurement guidelines included swapping to an electricity supplier who utilizes only renewable energy sources, light weighting of packaging projects, and exploring new uses for recycled packaging. Thus we see the new procurement guidelines being enrolled as part of the search and discovery activities in order to find the actions required to implement the new core value.

At this stage the increased actions being taken in the forming of associations, in the translation process to address the multiform problematization, had not resulted in a taken for granted understanding of the new core value. This prompted the MD to act at the beginning of 2008 through reviewing the four EPMs used as a diagnostic control by the operations department. From this he selected one, waste minimization, and indicated that this should be the one that all production facilities focus on. Thus the MD signaled that for the operations department the waste minimization EPM should become their interactive control.

The EPM measured the percentage of waste produced in the production process that was being recycled. In order to gain commitment to this EPM being used interactively and actions being taken to improve the performance in relation to this EPM, the MD shifted the targeted performance from ninety percent to ninety nine percent. In essence the MD altered the identity of the EPM in order for it to more effectively act upon the various production networks. Two production plants, one of which was Christchurch, had previously been comfortably exceeding the ninety percent target. The Christchurch Production Planning Manager's reaction to the change in the target is explained in the following:

"I thought these guys need their heads read, no one can get ninety-nine, it can't be achieved. And that was it, so I had a word [...] I sent my manager a couple of 
emails that I was pretty hacked off because it's part of but it's not my main job, I've got $[\ldots]$ all my other responsibilities and to have to sort of somehow endeavour to lift those levels, I mean you normally go up in stages don't you, anyone's normal quota would, but I must say, now I'd probably say that they had [...] foresight."

Thus the shifting of the target was initially meet with anger by many within Kiwi, including the Christchurch Production Planning Manager, as they believed they had done everything they could with their available resources to be above the target before it shifted. However the shifting of the target had two immediate and positive outcomes. The first of these was that the EPM began to be used interactively with all levels of the operations department monitoring and discussing the performance against the target. This included production facilities that had poor performance seeking advice from the recognized leaders in this area including the Christchurch Production Planning Manager. Secondly it forced the recognized leaders to start to scan for opportunities to improve their performance against the new target. In the case of the Christchurch Production Planning Manager this resulted in the fortuitous find of an external organization that specialized in recycling dry waste through an article about them in the local newspaper (The Press 2008). With the assistance of this organization they were able to improve their performance to consistently meet the new target of ninety nine percent recycling.

Also in 2008 the spokesperson for the network being assembled, the CFO, instigated a project to enroll a new management control. That is, the CFO put into place a project to calculate Kiwi's carbon footprint. The CFO selected one of his direct reports, the Project Manager Finance, to head up the project. In her words the carbon foot printing project came about as follows:

"Effectively we just looked at what was happening and [...] the potential of the ETS

[The New Zealand Government's Carbon Emissions Trading Scheme] coming in as well $[\ldots]$ and what was happening within the group and where things were at $[\ldots]$ the group was starting to look at carbon footprint [...] for the Australian business [...] but we were also wanting to look at it at the same time as opposed to [...] to wait" 
It was decided that 2007 would provide the base year for the project as it was the latest complete year for which data was available. The challenge of collecting the data given the complexity of the business was significantly underestimated resulting in the project over running the initial time frame. It also led to the Project Manager Finance commenting that personnel with an accounting background were probably best suited for the job of compiling and calculating carbon footprints. This was due to having a good holistic understanding of the organization combined with experience of using spreadsheets to collate and manipulate data.

Some actors within Kiwi, such as the Project Manager Finance, held an expectation that the enrolment of the carbon footprint would allow for the difficulties being experienced with the multiform problematization to be overcome. That is, an expectation existed that it would provide the necessary understanding of sustainability, it would enable Kiwi to become an emerging leader, and it would put an identity to those that would judge Kiwi as such. It would achieve this through bringing focus to the many sustainability initiatives occurring across the organization and enabling them to act together to address the multiform problematization. That is, once the base year was calculated the carbon footprint would take a prominent role within the network and through being used interactively it would act to draw together existing initiatives and provide direction to drive future initiative.

The initial calculation of the base year provided surprising results. Prior to this calculation Kiwi was expecting their heaviest carbon (or carbon equivalent) areas, given they were manufacturers, to be from their production processes and the vehicles they use for their sales reps and delivery drivers. Hence discussions prior to this calculation had solely been around strategies to reduce emissions from these sources. However the calculation of the base year carbon footprint expanded the scope of these discussions in a surprising way. This was due to these two areas being dwarfed by the total emissions from the refrigeration equipment that Kiwi maintained at their customers that alone tripled their carbon footprint. Further this calculation not only expanded the scope of discussion as to emission reduction strategies but also altered the very format of the carbon footprint report for the base year. That is, the report was expanded to show the results in total and also the results without the emissions from the refrigeration equipment. It was felt that if the total emissions alone were shown then the refrigeration equipment emissions would dominate the reader's attention to such a degree that the remainder of the results would not achieve visibility. Had the remainder of the results not been visible then they would not have the opportunity to act upon the reader.

The initiatives that would have come out of the carbon foot printing project were interrupted due to the Project Manager Finance going on long term leave in mid 2009. This typifies the types of trials of strength faced during the time covered by this research that Kiwi was trying to address the multiform problematization and 
thereby develop an understanding of the new core value. Despite senior management support the initiatives that have been implemented had been reliant on the efforts of individual actors located at various parts of the Kiwi network. As sustainability is a contested and ambiguous concept (Ball and Milne 2005; Milne 1996) the data shows that each of these actors understood it in a different way. Hence the identity of sustainability required as part of the multiform problematization remained problematic. Thus their actions, of which we have outlined above, did not lead to a coherent strategy as their efforts were disjointed and they had limited resources at their disposal. This left the efforts of the actors particularly susceptible to trials of strength such as that of the Project Manager Finance going on long term leave. Other key actors, such as the Corporate Affairs Manager and the former Integrated Management Systems Manager, also took long term leave during this time and other important actors, such as the Project Manager Operations, were reassigned roles within Kiwi or the greater Koala / Eagle network resulting in loss of momentum in sustainability focused initiatives.

The situation that Kiwi found itself in at the end of 2009 was one where the translation around finding an understanding for the core value which required addressing the multiform problematization was still ongoing. A number of relatively major trials of strength, mentioned above, had resulted in the weakening and disjointing of the network being assembled. Foremost of these trials of strength was the departure at the beginning of 2009 from the network of the spokesperson, the CFO. Although he had stopped being the official spokesperson for this network for a year prior to leaving he was still seen as the leader that gave legitimacy to the network. His replacement as the spokesperson of this network, the GM Corporate Affairs, also left the Kiwi network within a week of the CFO further weakening and disjointing the assembled network.

Probably the greatest trial of strength that this network faced was the 2008/09 economic recession. This resulted in even fewer resources being available. The biggest impact of the recession, however, was that it put the Kiwi network's focus firmly back on economic profit. Gray and Milne $(2002,68)$ suggest that "[e]qually it is both obvious and well established in research that any organization facing a conflict between its financial performance (most obviously performance affecting share price and dividend) and its social or environmental performance is bound to give preference to the financial in all but the most extreme cases." Thus, as economic profit is firmly embedded in Kiwi's formal belief systems it naturally took precedence over sustainability which only featured in the informal belief systems. The potential of the economic recession to act as a powerful counter-actor came into focus with New Zealand's hosting of the 2011 Rugby World Cup. The decision was taken in 2010 to reassign all available resources, such as the Project Manager Finance, into maximizing the 
financial benefits gained by Kiwi during this event. Thus it was signaled that the new core value, at least for the short term, was no longer a focus for the organization.

It is important to note that, while experimentation had failed to provide an understanding of the actions required to put in place the core value, traces of it remained even after it ceased to exist. That is there was continued use of other management controls that had identities imposed as a result of the search and discovery activities created by the core value. An illustrative example of this is the sustainability focused procurement guidelines. Prior to the introduction of the new core value this technical control had been based on standard profit orientated procurement guidelines. The introduction of the new core value, a social control, resulted in the profit orientated procurement guidelines being transformed in order to reflect the new beliefs around sustainability. Hence we see that even after the core value, the social control, ceased to exist within the organization that technical controls, such as the sustainability focused procurement guidelines, have elements of these social control embedded within them. Hence we see how and why controls are best thought of, in line with the comments of Chua and Mahama (2007), as being a blend of technical and social elements. We now turn in the next section to outlining the implications that we draw from this data.

\section{Implications}

In the previous section we provide an overview of the translation processes at Kiwi of developing a new core value. Further we show how this process acts upon and in turn is acted upon by the other LOC. The data suggests that the translation process began as a result of the efforts of the associated networks of Koala and Eagle who signaled it as an area of strategic importance and uncertainty that had the potential, if left unchecked, to affect the organization's performance. This resulted in a translation at Kiwi in order to try and establish the new core value. This initially involved the NZLT developing a description for the core value. This understanding was that Kiwi wanted to be seen as an emerging leader in relation to sustainability. Based on the enrolment of the core value the translation continued and focused on the multiform problematization the description created. This prompted search and discovery activities to develop an understanding of what actions were required to realize the new core value. The multiform problematization was that identities needed to be developed for the interrelated problems of what sustainability is, what it meant to be an emerging leader in relation to sustainability, and what was the identity of those who would judge Kiwi as a sustainability leader. It can be seen that the translation now involved many different actors within Kiwi trying many different things in order to identify and impose the identities required to find solutions for the multiform problematization. This is 
an example of what Ahrens and Chapman $(2006,825)$ describe as "[...] actors in the field are - depending on the specific motivations that grow out of their particular practices - also developing, testing, discarding, or refining suitable theories that help them understand the logic of the social systems within which they work." Thus we see that it is the need to provide an understanding of what actions are required in practice that prompts actors to undertake the search and discovery activities that have been ascribed to core values. That is, the search and discovery activities are aimed at exploring the practical relevancy of the new core value.

Focusing on the process through which a new core value is developed provides another implication. In tracing the associations that form to make up the translation we were able to discern the management controls enrolled into the process. Most importantly, adding weight to the findings of Mouritsen et al (2009), we are able to understand how these management controls rather than merely controlling the implementation of intended strategy are able to act to assist with defining the actions required to implement the new core value in practice. This is in line with the comment of Chua and Mahama $(2007,78)$ that "[a]ccounting then was not only a medium for the construction of corporate identity but an outcome of the identities constructed." In other words, the management controls within the process not only assist in implementing the new core value but also help it to develop and as a result cause it to change. We also note that in doing so some of these management controls change identities, such as the waste minimization metric moving from being used diagnostically to interactively. Finally during this process some of these management controls also impose new and unexpected identities on other management controls, such as the carbon footprint calculation changing the format of the carbon footprint report.

Further the example of the carbon footprint at Kiwi also provides evidence of how management controls can act upon other actors within this translation, just as the example of Latour's (1991) weight attached to the European hotel key. We can illustrate this with reference to the concerns of Ball and Milne (2005) who argue that the biggest deficit of current MCS is the lack of ecological literacy in organizations. As we describe above the carbon footprint provided Kiwi with surprising understandings of the refrigeration equipment effect on their total emissions. In terms of the Project Manager Finance who was given the job of producing the carbon footprint and related report we see that:

"I mean beyond, yeah, whatever I thought originally with this and [...] in the initial stages I possibly approached it a bit more like an accountant in terms of, you know, it's a report, it's got numbers coming in one end and, you know, graphs and reports 
coming out the other end. [...] That was very naïve, in a very narrow, narrow way of thinking about it $[\ldots]$ there is so much more to it and I faced an incredibly [...] complex process to pull together [...] just even to understand actually the type of emissions that need to come in here and the different parts of the business that actually create those $[\ldots]$ it's been a very complex process."

Thus through the process of calculating the carbon footprint the ecological outlook of the Project Manager Finance changed. Further this implication is in line with the research of Kober et al (2007). Through focusing on the two way influence between strategy and MCS, Kober et al (2007) have shown that MCS constantly evolve and in doing so alter the very strategy they are there to help implement. Here we have shown how, during the process of developing core values, other management controls develop, and as a result are transformed by the new core value, or act upon and change the core value.

Following on from this is an important implication to emerge from the data. The translation proved to be constantly susceptible to trials of strength and anti-programs, so much so that it, at least temporarily, disappeared from Kiwi. However, even with the eventual disappearance of the core value traces of it remained. Specifically, other management controls that had been transformed by the core value remained even with the disappearance of the core value itself. This was seen in the example of the procurement guidelines, which had become altered to include requirements around sustainability issues as a result of the new core value.

Further, if we understand the procurement guidelines as a boundary control then this also has implications for the LOC framework as a whole. Specifically Chua and Mahama (2007) critique the LOC for their distinction between social and technical controls. That is Simons (1995b) put core values forward as a positive social control and boundary controls as negative technical controls. From this example we can see that this division is a simplified representation of a complex reality. Our data, including this specific example, shows that each and every management control utilized within an organization is laden with a form of belief control as a reflection of the underlying core values of upper management. Further, this specific example outlines how rather than being purely positive and negative controls, belief and boundary systems are closely related and designed to move actors in the same direction.

With reference to Simons (1995b, 159), as represented in figure 1 above, there is a recognition within the LOC description that this is a "dynamic relationship", thus acknowledging that this is a simplification of a complex and messy reality. As researchers that utilize LOC we must also acknowledge, similar to Latour and 
Woolgar's (1986, 36-37) scientists, the limitations of using any such framework. Hence the LOC framework provides a useful and insightful way of dividing controls into a classification based on their social or technical nature. However, in practice we should be aware that technical controls contain elements of social control in them.

Finally, before we conclude in the next section, we note that the focus on senior management, as put forward in the LOC framework, is consistent with the notion that it is they who usually are in a position to set the objectives and goals for the organization. Further, some researchers (for example Abernethy and Chua 1996; Ferreira and Otley 2009) note that the objectives and goals senior management select are not necessarily the ones that will benefit the organization as a whole. However Chua (2007, 491) questions whether "[...] operational managers simply 'implement' some higher edict or do they actively devise new strategies as they adapt, translate and make up strategies 'on the ground' in the face of shifting contingencies and unexpected obstacles?" Our case study data supports the notion that operational managers are actively involved in the translation processes of developing core values but also suggests that they only permeate the organization to the level of these managers. For employees beyond this level it is irrelevant for them to have anything beyond a very general level of understanding. Rather their actions are driven towards implementing the goals and objectives of managers within the organization through the use of the other three levers of control. Hence when we observed, for instance, sales reps we saw that they were aware of some of the initiatives being taken with regard to sustainability such as the replacement of their vehicles with the more fuel efficient VW Golf. However the sales reps actions were being driven by the boundary systems, diagnostic control systems, and interactive control systems that related directly to their daily routines. It was clear that all of these controls had the aim of increasing sales and market share. Thus, they were relatively unaware and did not seem to care about the existence or development of the core value focusing on sustainability. This lack of understanding or knowledge of the core values did not inhibit them from pursuing what they were required to do by Kiwi. Rather the management controls in place effectively acted upon them to motivate them to strive to increase sales and market share and, as we outline above, were all embedded with elements of the core values through which belief control was enacted. Thus our data supports Chua's $(2007,491)$ statement that "[...] strategy may not be some activity reserved for 'men in high places' but resides instead in daily routines and activities that translate the abstract ideals of senior managers."

\section{Conclusion}


The aim of this paper was to examine core values and Simons LOC. Specifically we aimed to provide an understanding of how core values develop and the role of other management controls within this process. In order to investigate this we collected data from a case study site, Kiwi, an organization attempting to implement a new core value. Through this investigation we provide further understanding of the LOC framework. Specifically, we provide an understanding of how core values create search and discovery activities. This is motivated by the needs of actors to find practical relevance of the core value within their context. These search and discovery activities in turn develop the core value and other management controls are created and transformed. This process also embeds in the organization the beliefs of the core values translated via the management controls that were created or transformed. Hence we provide evidence that management controls carry elements of social as well as technical control. The combination of social and technical aspects within any given management control highlights how, through belief control, strategy is enacted in the daily routines of all actors within an organization.

These findings provide new meanings for the extant MCS literature. Specifically they have relevance to Mundy's $(2010,501)$ statement that "[...] these definitions are stated in broad, value-laden terms, because the purpose of a belief system is to inspire organizational search and discovery without prescribing the precise nature of the activities." While prior research shows that core values have the purpose of inspiring activities of search and discovery, it does not provide detailed insight into how this process occurs. In this paper we have shown that initially the translation provides a descriptive understanding that then provides the space for the translation to continue. That is, provides the inspiration for the actors who then undertake activities of search and discovery in an effort to impose an identity for the core value in relation to their own context. Hence we show that one of the ways in which core values inspire search and discovery is through compelling actors to take action to understand what must be done in order to achieve what the core value describes. Further these core values do not prescribe the precise nature of the activities as developing an understanding of these activities is the very objective of the process of search and discovery.

We note that in the case study the translation was still ongoing when we exited the field with the core value, at least in the short term, disappearing from the organizations. However we believe that due to the importance of the issue of sustainability and publically available evidence that this core value is one that will return to the agendas' of the NZLT at Kiwi sometime in the future. However, due to the complexity of the multiform problematization the translation may stretch on for the foreseeable future and may in fact never achieve a black boxed understanding for Kiwi. We believe this to be due to this core value focusing on 
sustainability, which is a complex and ambiguous concept (Ball and Milne 2005). As is the case for Mouritsen and Flagstad $(2005,211)$ "[t]he black box is not only "leaky" as Callon and Latour tell us, in this case it was never truly closed even if those who wanted and needed it most designed it." Future research could examine a less ambiguous situation where researchers are more likely to observe the translation for the core value in question resulting in a black boxed understanding. However, finding a less contentious situation that provides a suitable context for this type of research may prove to be problematic. That is through using the context of sustainability we were able to observe a translation that may not have been so drawn out in other contexts. In many other contexts the spatial and temporal elements may have been such that they would have made the translations indiscernible. In this situation the researcher may only be able to verify the existence of a new core value through its formal inscription in the organization mission, vision, or credo. Should it be possible to find such a context then, beyond providing conformation of our findings, this may also give more insight into when, how and why a core value becomes inscribed into the formal belief systems such as mission and vision statements.

Due to focusing on core values we have specifically chosen to utilize Simons LOC. However in using Simons LOC we are aware that they are not without criticism. One of the criticisms Ferreira and Otley (2009, 266) note is that "[...] in some organizations, such as subsidiaries, belief and boundary systems may be largely beyond the domain of control of the subsidiary." As this case study follows the translation process in the New Zealand operations of a large Australian listed company our results may potentially suffer from this weakness. However, as we mention above, we establish that the case study organization largely operates as if it were a wholly New Zealand owned company. Thus while they were influenced by both Koala and Eagle as to what their core values should be they had the freedom to develop their own based on their unique New Zealand context.

This research is distinct from previous research that looks at the formalization of controls from a lifecycle perspective (see for example Davila 2005; Granlund and Taipaleenmaki 2005). The case study organization is a relatively mature one that did not undergo changes in life-cycle during the study. Thus the use and development of a core value and changes in the wider LOC were being driven by strategic uncertainty rather than changes in the current state of the life-cycle.

In this paper we contribute to the holistic understanding, from a process oriented view, of MCS whereby the case organization was seen as an ever changing network of actors including management controls. Hence here we have added to works such as Kober et al (2007) in seeing senior managers experimenting and 
developing the controls they need in order to help address the strategic uncertainty they face. More importantly we have demonstrated, in line with Hansen (2011) that research that combines both performative and ostensive understandings has much to offer in providing new insights. 


\section{References:}

Abernethy, M. A., and P. Brownell. 1999. The role of budgets in organizations facing strategic change: An exploratory study. Accounting, Organizations and Society 24 (3):189-204.

Abernethy, M. A., and W. F. Chua. 1996. A field study of control system "redesign": The impact of institutional processes on strategic choice. Contemporary Accounting Research 13 (2):569-606.

Ahrens, T., and C. S. Chapman. 2004. Accounting for Flexibility and Efficiency: A Field Study of Management Control Systems in a Restaurant Chain. Contemporary Accounting Research 21 (2):271-301.

Ahrens, T., and C. S. Chapman. 2006. Doing qualitative field research in management accounting: Positioning data to contribute to theory. Accounting, Organizations and Society 31 (8):819-841.

Ahrens, T., and C. S. Chapman. 2007. Management accounting as practice. Accounting, Organizations and Society $32(1-2): 1-27$.

Alcouffe, S., N. Berland, and Y. Levant. 2008. Actor-networks and the diffusion of management accounting innovations: A comparative study. Management Accounting Research 19 (1):1-17.

Ball, A., and M. J. Milne. 2005. Sustainability and management control. In Management control : theories, issues, and performance, edited by A. J. Berry, J. Broadbent and D. Otley. Houndmills, Basingstoke, Hampshire New York: Palgrave Macmillan, 314-337.

Baxter, J., and W. F. Chua. 2003. Alternative management accounting research - Whence and whither. Accounting, Organizations and Society 28 (2,3):97-126.

Bisbe, J., and D. Otley. 2004. The effects of the interactive use of management control systems on product innovation. Accounting, Organizations and Society 29 (8):709-737.

Briers, M., and W. F. Chua. 2001. The role of actor-networks and boundary objects in management accounting change: A field study of an implementation of activity-based costing. Accounting, Organizations and Society 26 (3):237-269.

Bruining, H., M. Bonnet, and M. Wright. 2004. Management control systems and strategy change in buyouts. Management Accounting Research 15 (2):155-177.

Cahan, S. F., and Z. Wei. 2006. After Enron: Auditor Conservatism and Ex-Andersen Clients. Accounting Review 81 (1):49-82.

Çaliskan, K., and M. Callon. 2009. Economization, part 1: shifting attention from the economy towards processes of economization. Economy and Society 38 (3):369-398. 
Callon, M. 1986a. The sociology of an Actor-Network: The case of the electric vehicle. In Mapping the dynamics of science and technology : sociology of science in the real world edited by M. Callon, J. Law and R. Arie. Basingstoke: Macmillan, 19-34.

Callon, M. 1986b. Some elements of a sociology of translation: domestication of the scallops and the fishermen of St Brieuc Bay. In Power, action and belief: a new sociology of knowledge?, edited by J. Law. London: Routledge, 196-233.

Callon, M. 1991. Techno-economic networks and irreversibility. In A Sociology of monsters : essays on power, technology, and domination, edited by J. Law. London: Routledge, 132-161.

Callon, M. 2007. What does it mean to say that economics is performative? In Do economists make markets? : on the performativity of economics., edited by D. A. MacKenzie, F. Muniesa and L. Siu. Princeton: Princeton University Press, 311-357.

Callon, M. 2009. Civilizing markets: Carbon trading between in vitro and in vivo experiments. Accounting, Organizations and Society 34 (3/4):535-548.

Callon, M., and B. Latour. 1981. Unscrewing the big leviathan: How actors macrostructure reality and how sociologists help them do so. In Advances in social theory and methodology : toward an integration of micro- and macro-sociologies edited by K. Knorr-Cetina and A. V. Cicourel. Boston: Routledge \& Kegan Paul, 277-303.

Chua, W. F. 1995. Experts, networks and inscriptions in the fabrication of accounting images: A story of the representation of three public hospitals. Accounting, Organizations and Society 20 (2,3):111-145.

Chua, W. F. 2007. Accounting, measuring, reporting and strategizing - Re-using verbs: A review essay. Accounting, Organizations and Society 32 (4-5):487-494.

Chua, W. F., and H. Mahama. 2007. The Effect of Network Ties on Accounting Controls in a Supply Alliance: Field Study Evidence. Contemporary Accounting Research 24 (1):47-86.

Collier, P. M. 2005. Entrepreneurial control and the construction of a relevant accounting. Management Accounting Research 16 (3):321-339.

Cuganesan, S., and R. Lee. 2006. Intra-organisational influences in procurement networks controls: The impacts of information technology. Management Accounting Research 17 (2):141.

Davila, T. 2005. An exploratory study on the emergence of management control systems: formalizing human resourcs in small growing firms. Accounting, Organizations and Society 30 (3):223-248.

Dermer, J. 1977. Management Planning and Control Systems. Homewood, IL:: Richard D. Irwin, Inc. 
Ferreira, A., and D. Otley. 2009. The design and use of performance management systems: An extended framework for analysis. Management Accounting Research 20 (4):263-282.

Granlund, M., and J. Taipaleenmaki. 2005. Managment control and controllership in new economy firms - a life cycle perspective. Management Accounting Research 16 (1):21-57.

Gray, B. 1990. The enactment of management control systems: A critique of Simons. Accounting, Organizations and Society 15 (1-2):145-148.

Gray, R. 2010. Is accounting for sustainability actually accounting for sustainability...and how would we know? An exploration of narratives of organisations and the planet. Accounting, Organizations and Society 35 (1):47-62.

Gray, R., and M. J. Milne. 2002. Sustainability Reporting: Who's Kidding Whom? Chartered Accountants Journal 81 (6):66-70.

Hansen, A. 2011. Relating performative and ostensive management accounting research: Reflections on case study methodology. Qualitative Research in Accounting \& Management 8 (2):108-138.

Justesen, L., and J. Mouritsen. 2011. Effects of actor-network theory in accounting research. Accounting, Auditing \& Accountability Journal 24 (2):161 - 193.

Kaplan, R. S., and D. P. Norton. 1996. The balanced scorecard : translating strategy into action Boston, MA: Harvard Business School Press.

Kober, R., J. Ng, and B. J. Paul. 2007. The interrelationship between management control mechanisms and strategy. Management Accounting Research 18 (4):425-452.

Latour, B. 1986. The power of associations. In Power, action and belief: a new sociology of knowledge?, edited by J. Law. London: Routledge, 264-280.

Latour, B. 1987. Science in action: how to follow scientists and engineers through society. Cambridge, Mass.: Harvard University Press.

Latour, B. 1991. Technology is society made durable. In A Sociology of monsters : essays on power, technology, and domination, edited by J. Law. London: Routledge, 103-131.

Latour, B. 1999. Pandora's hope : essays on the reality of science studies Cambridge, Mass: Harvard University Press.

Latour, B. 2005. Reassembling the social: an introduction to actor-network-theory. Oxford: Clarendon.

Latour, B., and S. Woolgar. 1986. Laboratory life : the construction of scientific facts. Princeton, N.J.: Princeton University Press. 
Law, J. 1992. Notes on the theory of the actor-network: Ordering, strategy, and heterogeneity. Systemic Practice and Action Research 5 (4):379-393.

Law, J. 1999. After ANT: complexity, naming, and topology. In Actor network theory and after edited by J. Law and J. Hassard. Oxford: Blackwell Publishers

MacKenzie, D. 2009. Making things the same: Gases, emission rights and the politics of carbon markets. Accounting, Organizations and Society 34 (3-4):440-455.

Milne, M. J. 1996. On sustainability; The environment and management accounting. Management Accounting Research 7 (1):135-161.

Ministry for the Environment. 2009a. On Tap? Attitudes, behaviours, and perceptions of household water use informing demand management. Wellington, 54.

Ministry for the Environment. 2009b. Our Rivers: Trends in water quality. Wellington, 2.

Ministry for the Environment. 2009c. Our Water: Groundwater quality. Wellington, 1.

Mintzberg, H. 1978. Patterns in strategy formation. Management Science 24 (9):934-948.

Mouritsen, J., and K. Flagstad. 2005. The making of knowledge society: intellectual capital and paradoxes of managing knowledge. In Actor-network theory and organizing, edited by B. Czarniawska and T. Hernes. Copenhagen: Copenhagen Business School Press.

Mouritsen, J., A. Hansen, and C. Hansen. 2009. Short and long translations: Management accounting calculations and innovation management. Accounting, Organizations and Society 34 (6/7):738-754.

Mouritsen, J., A. Hansen, and C. Ø. Hansen. 2001. Inter-organizational controls and organizational competencies: episodes around target cost management/functional analysis and open book accounting. Management Accounting Research 12 (2):221-244.

Mouritsen, J., H. Mahama, and W. F. Chua. 2010. Actor-network theory and the study of inter-organisational network relations. In Accounting in networks, edited by H. Hakansson, K. Kraus and J. Lind. New York : London: Routledge, 292-313.

Mundy, J. 2010. Creating dynamic tensions through a balanced use of management control systems. Accounting, Organizations and Society 35 (5):499-523.

Nixon, W. A. J., and J. Burns. 2005. Management control in the 21st century. Management Accounting Research 16 (3):260-268.

Otley, D. T. 1980. The Contingency Theory of Management Accounting: Achievement and Prognosis. Accounting, Organizations and Society 5 (4):413. 
Rosner, R. L. 2003. Earnings Manipulation in Failing Firms. Contemporary Accounting Research 20 (2):361408.

Simons, R. 1987. Accounting Control Systems and Business Strategy: An Empirical Analysis. Accounting, Organizations and Society 12 (4):357.

Simons, R. 1990. The role of management control systems in creating competitive advantage: New perspectives. Accounting, Organizations and Society 15 (1-2):127-143.

Simons, R. 1991. Strategic Orientation and Top Management Attention to Control Systems. Strategic Management Journal 12 (1):49.

Simons, R. 1994. How new top managers use control systems as levers of strategic renewal. Strategic Management Journal 15 (3):169.

Simons, R. 1995a. Control in an Age of Empowerment. Harvard Business Review 73 (2):80-88.

Simons, R. 1995b. Levers of control : how managers use innovative control systems to drive strategic renewal. Boston, Mass.: Harvard Business School Press.

Simons, R. 2000. Performance measurement \& control systems for implementing strategy. Upper Saddle River, N.J.: Prentice Hall.

Simons, R. 2005. Levers Of Organization Design: How Managers Use Accountability Systems For Greater Performance And Commitment Boston: Harvard Business School Press

Simons, R., H. Mintzberg, and K. Basu. 2002. Memo to: CEOs. Fast Company June (59):117.

Tessier, S., and D. Otley. 2012. A conceptual development of Simons' Levers of Control framework. Management Accounting Research 23 (3):171-185.

The Press. 2008. Waste recovery plant kind to environment. 12 March, 2.

Tuomela, T.-S. 2005. The interplay of different levers of control: A case study of introducing a new performance measurement system. Management Accounting Research 16 (3):293-320.

Vaivio, J. 1999. Exploring a 'non-financial' management accounting change. Management Accounting Research $10(4): 409-437$.

Verburg, P., K. Hamill, M. Unwin, and J. Abell. 2010. Lake water quality in New Zealand 2010: Status and trends, edited by National Institute of Water \& Atmospheric Research Ltd. Hamilton, 48.

Wackernagel, M., and W. E. Rees. 1996. Our ecological footprint : reducing human impact on the Earth. Translated by W. E. Rees. Vol. no. 9. Gabriola Island, B.C.: New Society Publishers. 
Widener, S. K. 2007. An empirical analysis of the levers of control framework. Accounting, Organizations and Society $32(7 / 8): 757-788$. 

the grand purpose

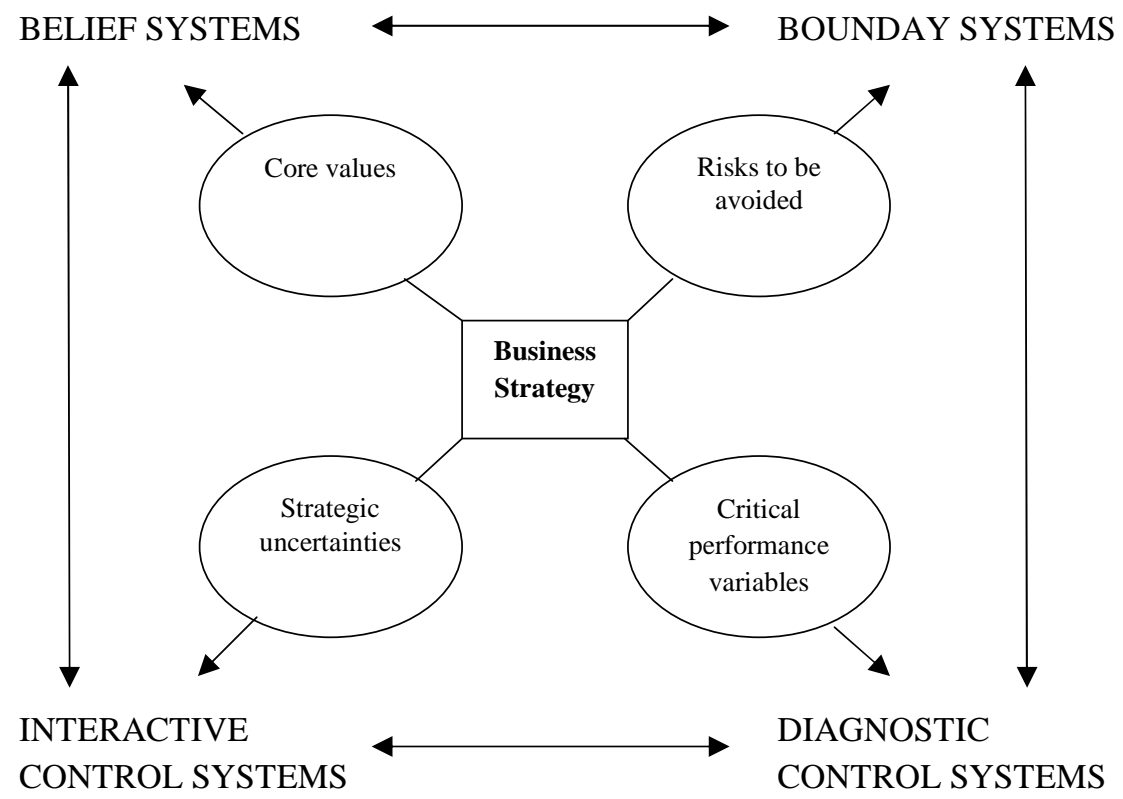

Strategy as

"patterns in action"

Positioning for tomorrow
Strategy as "plan"

Getting the job done

Figure 1 The Levers of Control: Copied from Figure 7.3 “A Dynamic Relationship” (Simons 1995, 159)

\begin{tabular}{|l|c|c|}
\hline \multicolumn{2}{|c|}{ Internal Only } & 3 \\
\hline Corporate presentation attended & & \\
\hline Interview hours & 23.5 hours & \\
\hline Number of interviews & 23 & \\
\hline Observation hours & 19 hours & \\
\hline Number of observations & 18 & \\
\hline Documents: & 51 & 3 \\
\hline General artifacts & 4 & 55 \\
\hline Media & 13 & \\
\hline Notes & 46 & \\
\hline
\end{tabular}

\section{TABLE 1}

Summary of Data 